Cronfa - Swansea University Open Access Repository

This is an author produced version of a paper published in :

Pediatrics

Cronfa URL for this paper:

http://cronfa.swan.ac.uk/Record/cronfa27037

\title{
Paper:
}

Hutchings, H., Evans, A., Barnes, P., Demmler, J., Heaven, M., Healy, M., James-Ellison, M., Lyons, R., Maddocks, A., Paranjothy, S., Rodgers, S. \& Dunstan, F. (in press). Residential Moving and Preventable Hospitalizations. Pediatrics

This article is brought to you by Swansea University. Any person downloading material is agreeing to abide by the terms of the repository licence. Authors are personally responsible for adhering to publisher restrictions or conditions. When uploading content they are required to comply with their publisher agreement and the SHERPA RoMEO database to judge whether or not it is copyright safe to add this version of the paper to this repository. http://www.swansea.ac.uk/iss/researchsupport/cronfa-support/ 


\section{Residential Moving and Preventable Hospitalizations}

Hayley A Hutchings, PhD, ${ }^{1}$ Annette Evans, MSc, ${ }^{2}$ Peter Barnes, MSc ${ }^{3}$, Joanne C Demmler, PhD, ${ }^{4}$, Martin Heaven, MPH, ${ }^{4}$ Melanie A Healy, PhD,${ }^{4}$, Michelle James-Ellison, MSc, ${ }^{3}$, Ronan A Lyons MD, ${ }^{4}$ Alison Maddocks, BSc, ${ }^{5}$ Shantini Paranjothy, PhD,${ }^{2}$ Sarah E Rodgers PhD, ${ }^{4}$ Frank Dunstan DPhil, ${ }^{2}$

\section{Pediatrics, 2016}

DOI: 10.1542/peds.2015-2836

${ }^{1}$ Patient and Population Health and Informatics Research (PPHI),

Swansea University Medical School,

Singleton Park,

Swansea.

SA2 8PP.

UK

Corresponding author: HA Hutchings

Email: h.a.hutchings@ swansea.ac.uk

Tel: $+44[0] 1792513412$

Fax: + $44[0] 1792513423$

${ }^{2}$ Cochrane Institute of Primary Care and Public Health, Cardiff University, Heath Park, Cardiff, UK.

${ }^{3}$ Abertawe Bromorgannwg University Health Board (ABM UHB), Singleton Park, Swansea, UK.

${ }^{4}$ Farr Institute, Swansea University Medical School, Swansea University, UK.

${ }^{5}$ Public Health Wales NHS Trust, St David's Park, Carmarthen, UK.

\section{Short Title}

Residential Moving and Preventable Hospitalizations

Non-standard abbreviations

CI- confidence interval

IRR- incidence risk ratio

$\mathrm{PPH}$ - potentially preventable hospitalizations

SAIL- Secure Anonymised Information Linkage

WECC- Welsh Electronic Cohort for Children

\section{Key words}

Residential mobility, children, cohort, potentially preventable hospitalization

\section{Funding source}

This project was funded through a number of grants. The Welsh Government New Ideas Social Research Fund supported the initial research. The study was also supported by two UK research centres. The Centre for the Development and Evaluation of Complex Interventions for Public 
Health Improvement (DECIPHer) is a UKCRC Public Health Research Centre of Excellence. Funding from the British Heart Foundation, Cancer Research UK, Economic and Social Research Council (RES-590-28-0005), Medical Research Council, the Welsh Assembly Government and the Wellcome Trust (WT087640MA), under the auspices of the UK Clinical Research Collaboration, is gratefully acknowledged.

The Centre for the Improvement of Population Health through E-records Research (CIIPHER) is one of four UK e-health Informatics Research Centres within the Farr Institute funded by a joint investment from: Arthritis Research UK, the British Heart Foundation, Cancer Research UK, the Chief Scientist Office (Scottish Government Health Directorates), the Economic and Social Research Council, the Engineering and Physical Sciences Research Council, the Medical Research Council, the National Institute for Health Research, the National Institute for Social Care and Health Research (Welsh Government) and the Wellcome Trust (Grant reference: MR/K006525/1).

\section{Financial Disclosure Statement}

None

\section{Conflict of Interest Statement}

No conflicts of interest

\section{What's known on this subject}

Frequent residential mobility is associated with behavioural and emotional effects in children and may result in increased health care utilisation. Moving home can present an injury risk for children, resulting in hospital admissions and morbidity that is potentially preventable.

\section{What this study adds:}

We identified that children who move just once in their first year of life had more potentially preventable hospitalizations compared with children who do not move. 


\section{Author Contributions}

Professor Hutchings: conceptualized and designed the study; performed the experiments; analyzed the data; and led on writing the manuscript. Ms Evans: contributed to the design of the study; performed the experiments; led on the data analysis; contributed to cleaning and validation of datasets; and helped draft the manuscript. Drs Barnes, Maddocks and JamesEllison: contributed to the design of the study; provided clinical, child health and policy input; and helped draft the manuscript. Drs Demmler and Healy: contributed to the design of the study; performed the experiments; contributed to cleaning and validation of datasets; and helped draft the manuscript. Mr Heaven contributed to the design of the study; contributed to cleaning and validation of datasets; and helped draft the manuscript. Professor Lyons contributed to the design of the study; provided public health, data linkage and policy input; and helped draft the manuscript. Drs Paranjothy and Rodgers contributed to the design of the study; performed the experiments; and helped draft the manuscript. Professor Dunstan contributed to the design of the study; performed the experiments; provided senior support for statistical data analysis; and helped draft the manuscript. 


\section{Abstract \\ Objectives}

To investigate the association between moving home in the first year of life and subsequent emergency admissions for potentially preventable hospitalizations.

\section{Methods}

We undertook a cohort analysis of linked anonymised data on 237,842 children in the Welsh Electronic Cohort for Children. We included children born in Wales between 1 April 1999 and 31 December 2008. The exposure was the number of residential moves from birth up to 1 year. The main outcome was emergency admissions for potentially preventable hospitalizations (PPH) between the age of 1 and 5 years.

\section{Results}

After adjustment for confounders, we identified that moving home frequently in the first year of life was associated with an increased risk of emergency PPH between the ages of 1 and 5 when compared to not moving. We found significant differences associated with $2+$ moves for the following: ear, nose and throat infections (Incidence Risk Ratio (IRR) 1.44, 95\% CI 1.29-1.61); convulsions/epilepsy (IRR 1.58, 95\% CI 1.23-2.04); injuries (IRR 1.33, 95\% CI 1.18-1.51); dehydration/gastroenteritis (IRR 1.51, 95\% CI 1.21-1.88); asthma (IRR 1.61, 95\% CI 1.19-2.16); influenza/pneumonia (IRR 1.15, 95\% CI 1.00-1.32); and dental conditions (IRR 1.30, 95\% CI 1.03-1.64 for $1+$ moves).

\section{Conclusions}

Children who move home in the first year of life are at substantially increased risk of emergency admissions for PPH in early childhood. Further research that focuses on enhancing health and social support services for highly mobile families, educating parents about safety risks and improving housing quality is warranted. 


\section{Introduction}

The impact of moving home (residential mobility) during childhood on health outcomes has previously been studied but the evidence to date has largely focused on behavioural, emotional and educational outcomes in children ${ }^{12}$. Frequently moving home in childhood is associated with poorer health outcomes in later life $\mathrm{f}^{34}$, including higher rates of drug use $\mathrm{e}^{5}$, smoking ${ }^{6}$ and attempted suicide $^{178}$. Most research relating to the effects of residential mobility on health outcomes is from North America where rates of mobility are high. Studies in Canada, USA and Finland have examined the association between moving home and healthcare utilization, with conflicting results. Studies in the USA and Canada reported that children who had frequently moved home in childhood were less likely to have a regular site for healthcare, were more likely to use an emergency department, see multiple providers of healthcare and have less continuity of care $^{1}$. However, researchers in Finland found no association between address changes and use of primary care services 9 . The Millennium Cohort study explored mobility and some health outcomes $^{10}$, and a comparative UK and US study explored the effects of mobility on health care utilization $^{11}$ but we are not aware of any UK studies that have examined the effects of early residential moves on future hospitalizations.

One mechanism through which an association between mobility might arise may be due to causal pathways, for example because of severed links with professionals, or due to stress associated with moving. Supporting families with infants is a key role of health care providers following the birth of a child. Frequently moving home, particularly during infancy, may prevent the development of relationships with health professionals (especially in relation to early years' health services $)^{12}$, affect continuity of care, and appropriate monitoring and follow up of health 
problems. Frequently moving home also presents an increased risk of unintentional injury for young children ${ }^{101314}$. This could be due to the unfamiliar environment, or a combination of this and the introduction of hazards in the home due to inadequate housing standards.

Other factors that are likely to have an impact on hospitalization may be considered as confounders and should be dealt with in the adjustment of analyses as they could cause spurious associations between mobility and hospitalisations. For example, deprived families are thought to move home more frequently and are more likely to live in damp and poorly ventilated housing, causing them to have increased illness rates due to infections and respiratory related conditions $^{15}$. Research has also recognized that family structure can result in stress, family hardship and changes in the quality of the family home ${ }^{16}$, leading to significant differences between children who have experienced a family breakdown and those who have not ${ }^{16}{ }^{17}$. Since family transitions are linked with other changes including moving house, school and/or neighbourhood $^{16}$, it is possible that moving home frequently could potentially be a marker of families needing social support.

Moving frequently may therefore increase the likelihood of living in substandard housing with associated hazards. It is likely that some of the effects of moving home, such as accident risk due to unfamiliar surroundings are likely to occur in the immediate period following a move, and until a child has adapted to their surroundings. It is possible however that some outcomes, such as infections and vaccine preventable conditions may occur a longer period after the move because the risks are likely to still be present. It is likely that different risks may present at 
different childhood developmental stages, for example during transitions from not moving to crawling and walking; or when routines change such as when starting nursery or childcare.

Potentially preventable hospitalizations (PPH) have been defined as "hospitalisations that may be preventable with high quality primary and preventive care. These hospitalisations may be avoided if clinicians effectively diagnose, treat and educate patients, and if patients actively

participate in their care and adopt healthy lifestyle behaviours"18. If there was a true association between frequently moving home and under-utilization of regular primary care services, then this may result in an increase in emergency PPH in children who have moved home frequently during early childhood. No studies to date have examined the association between frequently moving home and emergency PPH.

The ability to measure movement between addresses and link data from different sectors, such as education, work or crime, produces exciting research opportunities ${ }^{19}$. In this paper we utilized the Secure Anonymised Information Linkage (SAIL) databank to examine the association between moving home in the first year of life and emergency PPH in a large population based cohort of children born in Wales, United Kingdom (UK).

\section{Methods}

\section{Data sources}

This study used data from the Wales Electronic Cohort for Children (WECC) held within the SAIL databank ${ }^{20}$. SAIL is part of the national research infrastructure in Wales based at Swansea University, UK and is a relational database capable of linking anonymized data at individual and 
household level across many health and health-related data sets ${ }^{21}$. The SAIL databank uses a robust array of privacy-protecting techniques to overcome the confidentiality and disclosure issues in health related warehousing. As part of privacy protection, SAIL does not hold identifiable demographic data (such as names and addresses) but uses anonymized linking fields (ALFs) produced by a National Health Service (NHS) trusted third party. This means that the information on individuals can be linked together from different datasets using the ALF and information at the household level can be linked together using a similarly constructed Residential Anonymised Linking Field (RALF) ${ }^{22} 23$, which is assigned to each child based on their current address using the Welsh Demographic Service (WDS) dataset. This is compiled from address changes provided by patients to their General Practitioner. This unique set-up enables longitudinal analyses to be undertaken on data for groups of individuals living together in the same household, including the ability to follow movement between residences over time ${ }^{19}$. Phase one of the WECC consists of linked anonymized records for over 800,000 children born or living within Wales between 1 January 1990 and 31 December 2008. The individual-level anonymized data on these children that were used for this study were obtained from numerous sources: the Welsh Demographic Service (WDS), a continually updated record of children living in Wales; community child health records from the National Community and Child Health Database (NCCHD); births and deaths from the Office for National Statistics (ONS); and inpatient data from the Patient Episode Database for Wales (PEDW).

\section{Cohort development}

We included all children in the WECC born and living in Wales between 1 April 1999 and 31 December 2008 (see Figure 1). We excluded children moving in to or out of Wales during the 
first year of life. Moves out of Wales were recorded but the outcome data after that time were not used. We also excluded stillbirths, infant deaths and children born with major congenital anomalies from this analysis. After exclusions, the final cohort size for analysis was 237,842 . The total length of follow-up of the cohort was 542,463 person-years, with mean length of follow-up 2.28 (SD 1.31) years for children from age 1 to 5 years old, accounting for differential loss for the end of the cohort (post 31/8/2008), a house move after age 1 year or death.

\section{Measure of exposure}

The focus of this study was to explore if moving in the first year of life had an effect on future potentially preventable hospitalizations that were unplanned. In this analysis we calculated the number of patient reported residential moves in the first year of life (i.e. from birth to age 1 year). We wanted to explore the potential effects of move frequency and ordered them into categories $(0,1,2+$ wherever possible), as appropriate and in line with other research that has examined the effects of residential mobility on health and educational outcomes ${ }^{12}$. Where numbers were small, residential mobility was limited to two categories $(0,1+)$.

\section{Measurement of outcome}

We analyzed the data based on the emergency PPH outcome measures for a range of acute, chronic and vaccine preventable conditions between age 1 and 5 years (see Table 1 ). We chose the period up to 5 years to measure outcomes based on the availability of follow-up data. This period allowed us to capture risks that may present at different developmental stages. For example as babies start to move through crawling and walking they are likely to be presented with different injury risks (burns, falling, tripping etc). Also as babies are weaned from 
breastfeeding, they may be more at risk of infection or poisoning whilst their immune system is developing. When children start nursery or school they are also likely to be more at risk of illnesses, infection and injury. We identified specific ICD10 codes on the basis of previously published research on $\mathrm{PPH}^{1824-26}$. For all codes with the exception of vaccine preventable conditions, appendicitis and injuries we required the appropriate code to be in the primary diagnostic position in individual level hospital records ${ }^{27}$. Vaccine preventable conditions and appendicitis were identified from any coding position according to guidance from previous studies $^{14}$ 19-21. Causes of injury codes are usually paired with nature of injury codes but not always in that order and hence reliance on primary position will not identify all cases.

\section{Confounding variables}

We adjusted for the following pre-defined confounding variables which were considered to have a possible effect on our outcomes: gender, parity, gestational age, maternal age at birth, maternal cigarette smoking at booking appointment (first trimester), maternal breast feeding status at birth or 6-8 weeks, material deprivation measured by the Townsend score ${ }^{28}$ of registered lower super output area (LSOA) at birth, multiple births, congenital anomalies, being small for gestational age (i.e. less than $10^{\text {th }}$ centile) and birth by caesarean section. Variables other than breastfeeding status (16.3\% missing) and maternal cigarette smoking (62.2\% missing) had few missing values and therefore only subjects with complete records for those variables were included. We imputed the breastfeeding status and maternal cigarette smoking data using multiple imputation based on chained equations (MICE) using the variables listed ${ }^{29}$. Estimates from 20 different imputations were combined using Rubin's rule ${ }^{30}$. 


\section{Statistical analysis}

We analyzed the data using Stata version 13. To examine PPH we fitted negative binomial regression models to the data (to account for differential loss to follow-up of the outcome measure from end of cohort (post 31/8/2008), a house move after age 1 year or death) to calculate person-years incidence risk ratios (IRR) (with 95\% confidence intervals). House moves and PPH categories (Table 1) were considered in univariate analysis. Where a significant association $(\mathrm{P} \leq 0.05)$ was found, categories were grouped as an All PPH variable (Table 2) and in individual categories (Table 3) for multivariate analysis. To avoid making assumptions of linearity we categorised those variables that could take many values and treated them as categorical variables. Maternal age was divided into five-year bands, with the exception of teenage mothers and those aged at least 40. Townsend deprivation scores were divided into quintiles

\section{Ethical approval}

National Research Ethics Service (NRES) guidance does not require ethical review for anonymised databank studies. We obtained approval from the independent Information Governance Review Panel (IGRP), whose membership includes Caldicott Guardians and other Information Governance professionals, lay people and representatives from the National Research Ethics Service (NRES) to use SAIL to answer the specific house moves research question $^{2021}$.

\section{Results}


Of the 237,842 children included in the cohort: $201,114(84.6 \%)$ never moved; $31,735(13.3 \%)$ moved once; and 4,993 (2.1\%) moved two or more times in their first year of life. Emergency $\mathrm{PPH}$ were associated with increasing numbers of residential moves for several confounders (Table 2). Table 4 illustrates the frequency of emergency PPH in each year for the period of follow up. The greatest rate of PPH was between the ages of 1 and 2 years, with decreasing frequency of PPH up to age 5. Non-movers showed a reduction in admissions over time, whereas movers had an increase in admissions for some PPH (asthma, dental conditions, vaccine preventable conditions and appendicitis). For the majority of time points and PPH, the movers had more PPH than the non-movers.

The percentage of children having 1 or more emergency PPH between the age of 1 and 5 years increased with increasing frequency of residential moves $(13.9 \%$ for children who did not move between age 0 and 1 compared with $16.4 \%$ for children who had moved 2 or more times). Compared to no moves, for children with one move in the first year of life the risk of a PPH between the ages of 1 and 5 years increased by $14 \%$ and for 2 or more moves the risk of PPH increased by $45 \%$ after adjusting for confounders. In the adjusted model, children of a younger mother, gestational age at birth, boys, a minor congenital anomaly or born by caesarean section were all independently associated with increased risk of emergency PPH. Regression analysis on the dataset without imputation of breast-feeding and maternal cigarette smoking missing data (complete case analysis) gave similar results. 
Increased frequency of residential moves in the first year of life resulted in an increased risk of all PPH (Table 3). We identified a significantly increased risk after controlling for confounders for: ear, nose and throat infections; convulsions and epilepsy; injuries;

dehydration/gastroenteritis; asthma; influenza/pneumonia; and dental conditions between the age of 1 and 5 years. In all cases the IRR was higher for $2+$ moves than for a single move. House moves in the first year of life were not shown to significantly increase the risk of PPH for acute appendicitis with generalized peritonitis; or other vaccine preventable conditions.

\section{Discussion}

Our study, in which we examined the effect of moving home on emergency PPH within early childhood, demonstrated that even a small number of moves appear to have a detrimental effect on subsequent health. We showed that residential moves are associated with an increased risk of being admitted to hospital for: ear, nose and throat infections; convulsions and epilepsy; injuries; dehydration/gastroenteritis; chronic asthma; influenza/pneumonia; and dental conditions between the age of 1 and 5 years. We also found similar associations for non-PPHs as those found for $\mathrm{PPH}^{31}$. Our findings concur with US studies that have reported increased utilization of emergency healthcare services and lack of engagement with primary care providers ${ }^{32-34}$. A key issue is whether these relationships are causal or reflect unmeasured residual confounding, the latter almost impossible to rule out in observational studies. Some factors such as a failure of families to engage with early years healthcare providers or the stress of moving may result in a causal pathway leading to an increased use of emergency departments. In addition, the decision whether to hospitalize may be influenced by level of primary care and social support which may lead to more hospitalizations in the highly mobile group. Other factors are more likely to be due 
to confounding, such as deprivation and family structure. Comparison of our findings with existing theories and empirical literature helps to shed light on this difficult question.

Most injuries to pre-school children happen at home ${ }^{14}$, with well-known risk factors documented including: low social class, psychosocial stress, an unsafe environment, and child development disorders ${ }^{35}$. The findings from our study illustrated that residential mobility in the first year of life was associated with an increased risk of emergency PPH from injury or poisoning. It is possible that this increased injury risk could be the result of moving to a new house and unfamiliar surroundings; less safe environments may be characterised by rental housing stock, or indicate a more chaotic lifestyle, not captured by the use of a coarse area based deprivation measure and other predictors used in the analysis. Our findings are similar to those from the Millennium Cohort Study; mobile families had more infant injuries and individual measures of deprivation and social class were included in the analysis ${ }^{10}$. Other researchers showed that in pre-school children, frequent home moves were more strongly associated with overall accident rates than family type ${ }^{14}$. Findings from a US study suggest that the stress of a family move may be a precipitating factor in the aetiology of unintentional burns, with moving children having approximately three times the rate of burns than those from the general population ${ }^{13}$.

A number of researchers have suggested a link between the frequency of home moves and the development of respiratory conditions or infections ${ }^{153637}$. Our findings reinforce previous work in illustrating that moving home frequently presents an increased risk of PPH for asthma, and ear nose and throat infections. We also found an increased residential mobility resulted in an increased risk of PPH for convulsions and epilepsy, dehydration and gastroenteritis, and 
influenza/pneumonia. A case-control study in which researchers examined whether house moves were a risk factor for the development of childhood asthma found a non-significant association between early home moves and the subsequent development of asthma ${ }^{38}$. Other studies have also shown strong associations between home moves in families with young children to previously inhabited, centrally heated dwellings and the subsequent development of childhood asthma $^{3940}$. It is suggested that moving home at an early age increases the risk of developing asthma, or is associated with other more important risk factors, such as increased general mobility and hence exposure to viral infections ${ }^{38}$. Similarly, it is thought that an increase in residential mobility, as an indicator of deprivation and living in a damp home, may be more important in the aetiology of asthma than exposure to any one individual allergen or pollutant ${ }^{40}$. Our study examined the number of residential moves only; we did not have information regarding the condition of residential properties.

We conducted this study using a large retrospective population-based cohort. Using SAIL we previously demonstrated the effects of moving home on school and educational attainment as a prelude to studying the complex inter-relationship between education and health ${ }^{2}$. A strength of this research was that the large size of the cohort and five year follow up, included sufficient frequencies for the outcomes of interest. Outcomes were collected in a standardised way, blinded to exposure status, facilitating rigorous comparison of the data.

A limitation of our study was that we had no information regarding the reasons for moving ${ }^{41}$. Not all children may be detrimentally affected by a move. For some it could represent a move into a more affluent area with better facilities and housing and therefore it would be expected to 
have a beneficial effect on their future health. It would be useful to examine whether individual moves were to a higher or lower level of deprivation and whether this influences the outcome. In addition, in our study, a residential move was defined as the change of address registered with the NHS. We also know that short term moves, and individuals not engaging with health service providers may result in moves not be registered with the NHS. This would lead to a misclassification of the number of moves and is likely to lead to an under-estimation of the effect of moving home. We did not examine details regarding the distance involved in moves, only their frequency in the first year of life. We recognize that moves may only be to next door or to quite a distance. However other research recently completed by the team using the same dataset found that moving between deprivation quintiles was not a significant predictor of hospital admissions (personal communication). Family structure is known to have strong influences on childhood outcomes $^{1617}$. We did not include details regarding the family structure in our analysis and would recommend further research to examine whether differences in family structure influence the outcome over and above moving home.

Further research is needed to determine whether the effects of residential mobility in early childhood on PPH persist in later childhood and adolescence and whether moves beyond the first year of life have similar effects. In addition further sensitivity analysis to explore the type and timing of PPHs could determine whether certain hospitalisations are linked to different childhood developmental stages. We found that children who move home had increased risk of PPH compared with those who are more residentially stable. Whether this effect is primarily due to the move, residual confounding for socio-economic status, or a mixture of both is difficult to ascertain completely. Some of the other published literature that adjusted for confounders, albeit 
in smaller studies such as the Millennium Cohort Study $(n=18,000)$, demonstrate similar findings.

The question is what to do about such findings? The PPHs due to moving home represent a systems failure and can be considered a safe-guarding issue. Our findings also have wider implications for policy makers both nationally and internationally. Consideration needs to be given to welfare reforms which, may for example result in moves by claimants. Policy makers need to be aware of the potential detrimental health effect that moving may have on families.

We found sizeable effects sizes, worthy of developing a targeted intervention. These interventions would be based on likely causal factors such as improving links with health care professionals and supporting parents who move. However, potential interventions aiming to help educate, support and monitor highly mobile families should be tested using rigorous designs before being completely rolled out. Further research including qualitative work is needed to understand the reasons behind residential mobility in early childhood and these causal factors. This could help identify families potentially at risk who should be offered additional support. Once we have a robust understanding of these factors, we can develop interventions for randomized controlled trials. 


\section{Acknowledgments}

This study makes use of anonymised data held in the Secure Anonymised Information Linkage (SAIL) system, which is part of the national e-health records research infrastructure for Wales. We would like to acknowledge all the data providers who make anonymised data available for research. Responsibility for the interpretation of the information supplied by SAIL is the authors' alone. 


\section{References}

1. Jelleyman T, Spencer N. Residential mobility in childhood and health outcomes: a systematic review. J Epidemiol Community Health 2008;62(7):584-92.

2. Hutchings HA, Evans A, Barnes P, Demmler J, Heaven M, Hyatt MA, et al. Do children who move home and school frequently have poorer educational outcomes in their early years at school? An anonymised cohort study. PLoS One 2013;8(8):e70601.

3. Bures RM. Childhood residential stability and health at midlife. Am J Public Health 2003;93(7):1144-8.

4. Oishi S, Schimmack U. Residential mobility, well-being, and mortality. J Pers Soc Psychol 2010;98(6):980-94.

5. DeWit DJ. Frequent childhood geographic relocation: its impact on drug use initiation and the development of alcohol and other drug-related problems among adolescents and young adults. Addict Behav 1998;23(5):623-34.

6. Lee D. Residential mobility and gateway drug use among Hispanic adolescents in the U.S.: evidence from a national survey. Am J Drug Alcohol Abuse 2007;33(6):799-806.

7. Qin P, Mortensen PB, Pedersen CB. Frequent change of residence and risk of attempted and completed suicide among children and adolescents. Arch Gen Psychiatry 2009;66(6):62832.

8. Haynie DL, South SJ, Bose S. Residential mobility and attempted suicide among adolescents: An individual level analysis. The Sociological Quarterly 2006;47:693-721.

9. Vuorinen HS. Family resources and children's use of primary health care services in Finland in 1979. Scand J Soc Med 1990;18(4):241-7.

10. Tunstall H, Cabieses B, Shaw R. The characteristics of mobile families with young children in England and the impact of their moves on neighbourhood inequalities in maternal and child health. Health and Place 2011;doi: 10.1016/j.healthplace.2011.11.009.

11. Bain DJ. Patient mobility and consulting behavior: a comparative study between the United Kingdom and the United States. J Fam Pract 1981;12(5):891-5.

12. Pearce A, Elliman D, Bedford H, Law C. Residential mobility and uptake of childhood immunisations: findings from the UK Millennium Cohort Study. Vaccine 2008;26(13):1675-80.

13. Knudson-Cooper MS, Leuchtag AK. The stress of a family move as a precipitating factor in children's burn accidents. J Human Stress 1982;8(2):32-38.

14. Wadsworth J, Burnell I, Taylor B, Butler N. Family type and accidents in preschool children. J Epidemiol Community Health 1983;37(2):100-4.

15. Lowry S. Housing and health: Families and flats. BMJ 1990;300(6719):245-7.

16. Mooney A, Oliver C, Smith M. Impact of family breakdown on children's well-being. Evidence review. London: Institute of Education, June 2009.

17. Carlson MJ, Corcoran ME. Family structure and children's behavioural and cognitive outcomes. Journal of Marriage and Family 2001;63:779-92.

18. Agency for Healthcare Research and Quality. AHRQ Quality Indicators. Guide to Prevention Quality Indicators: Hospital Admission for Ambulatory Care Sensitive Conditions. Version 3.1. Available from:http://www.ahrq.gov/downloads/pub/ahrqqi/pqiguide.pdf (Access date 10/10/2013), October 2001. 
19. Lyons RA, Ford DV, Moore L, Rodgers SE. Use of data linkage to measure the population health effect of non-health-care interventions. Lancet 2013.

20. Ford DV, Jones KH, Verplancke JP, Lyons RA, John G, Brown G, et al. The SAIL Databank: building a national architecture for e-health research and evaluation. BMC Health Serv Res 2009;9:157.

21. Lyons RA, Jones KH, John G, Brooks CJ, Verplancke JP, Ford DV, et al. The SAIL databank: linking multiple health and social care datasets. BMC Medical Informatics and Decision Making 2009;9:3.

22. Rodgers SE, Demmler JC, Dsilva R, Lyons RA. Protecting health data privacy while using residence-based environment and demographic data. Health Place 2012;18(2):209-17.

23. Rodgers SE, Lyons RA, Dsilva R, Jones KH, Brooks CJ, Ford DV, et al. Residential Anonymous Linking Fields (RALFs): a novel information infrastructure to study the interaction between the environment and individuals' health. J Public Health (Oxf) 2009;31(4):582-8.

24. Katterl R, Anikeeva O, Butlet C, Brown L, Smith B, Bywood P. Potentially avoidable hospitalisations in Australia: Causes for Hospitalisations and primary health care interventions. Available from: http://www.phris.org.au/phplib/filedownload.php?file=/elib/lib/downloaded_files/publica tions/pdfs/news 8388.pdf (access date 10/10/2013): Primary Health Care Research and Information service, July 2012.

25. Chen L, Lu HM, Shih SF, Kuo KN, Chen CL, Huang LC. Poverty related risk for potentially preventable hospitalisations among children in Taiwan. BMC Health Serv Res 2010;10:196.

26. Page A, Ambrose S, Glover J, Hetzel D. Atlas of avoidable hospitalisations in Australia: ambulatory care-senstive conditions: Public Health Information Development Unit, April 2007.

27. NHS Wales, Publich Health Wales Observatory. Patient Episode Database for Wales (PEDW). Available from: http://www.wales.nhs.uk/sitesplus/922/page/50308 (Access date 29/1/2014).

28. Townsend $\mathrm{P}$, Phillimore $\mathrm{P}$, Beattie A, editors. Health and deprivation. Inequality and the North. London: Croom Helm Ltd, 1987.

29. White IR, Royston P, Wood AM. Multiple imputation using chained equations: Issues and guidance for practice. Stat Med 2011;30(4):377-99.

30. Little RJA, Rubin DB. Statistical analysis with missing data. 2nd ed. New Jersey: John Wilesy and Sons, 2002.

31. Hutchings H, Rodgers S, Hyatt MA, Lyons R, Paranjothy S, Maddocks A, et al. Do children who move frequently have poorer health and educational outcomes? Final report to the Welsh Government 2012.

32. Mustard CA, Mayer T, Black C, Postl B. Continuity of pediatric ambulatory care in a universally insured population. Pediatrics 1996;98(6 Pt 1):1028-34.

33. Fowler MG, Simpson GA, Schoendorf KC. Families on the move and children's health care. Pediatrics 1993;91(5):934-40.

34. Duchon LM, Weitzman BC, Shinn M. The relationship of residential instability to medical care utilization among poor mothers in New York City. Med Care 1999;37(12):1282-93.

35. Kemp A, Sibert J. Childhood accidents: epidemiology, trends, and prevention. J Accid Emerg Med 1997;14(5):316-20. 
36. Shelter. Chance of a lifetime: The impact of bad housing on children's lives. 2006.

37. McCarthy P, Byrne D, Harrisson S, Keithley J. Respiratory conditions: effect of housing and other factors. J Epidemiol Community Health 1985;39(1):15-9.

38. Jones RC, Hughes CR, Wright D, Baumer JH. Early house moves, indoor air, heating methods and asthma. Respir Med 1999;93(12):919-22.

39. Hughes $\mathrm{CH}$, Baumer JH. Moving house: a risk factor for the development of childhood asthma? BMJ 1995;311(7012):1069-70.

40. Austin JB, Russell G. Wheeze, cough, atopy, and indoor environment in the Scottish Highlands. Arch Dis Child 1997;76(1):22-6.

41. Brown D, Benzeval M, Gayle V, Macintyre S, O'Reilly D, Leyland AH. Childhood residential mobility and health in late adolescence and adulthood: findings from the West of Scotland Twenty-07 Study. J Epidemiol Community Health 2012;66:942-50. 
Figure and Tables Legends

Figure 1: Selection of cohort for analysis

Table 1: ICD-10 codes for potentially preventable hospitalizations $(\mathrm{PPH})^{1824-26}$

Table 2: Negative binomial model of the frequency of the frequency of moving home from Age 0 to $<1$ year and all emergency $\mathrm{PPH}^{*}$ between the ages of 1 and 5 years $(n=237,842)$

Table 3. Negative binomial model of the frequency of moving home from age 0 to $<1$ year and all emergency PPH between the ages of 1 and 5 years $(n=237,842)$

Table 4 Potentially preventable emergency hospitalization incidence rates by year of follow-up and house move $(n=237,842)$ 
Figure 1: Selection of cohort for analysis

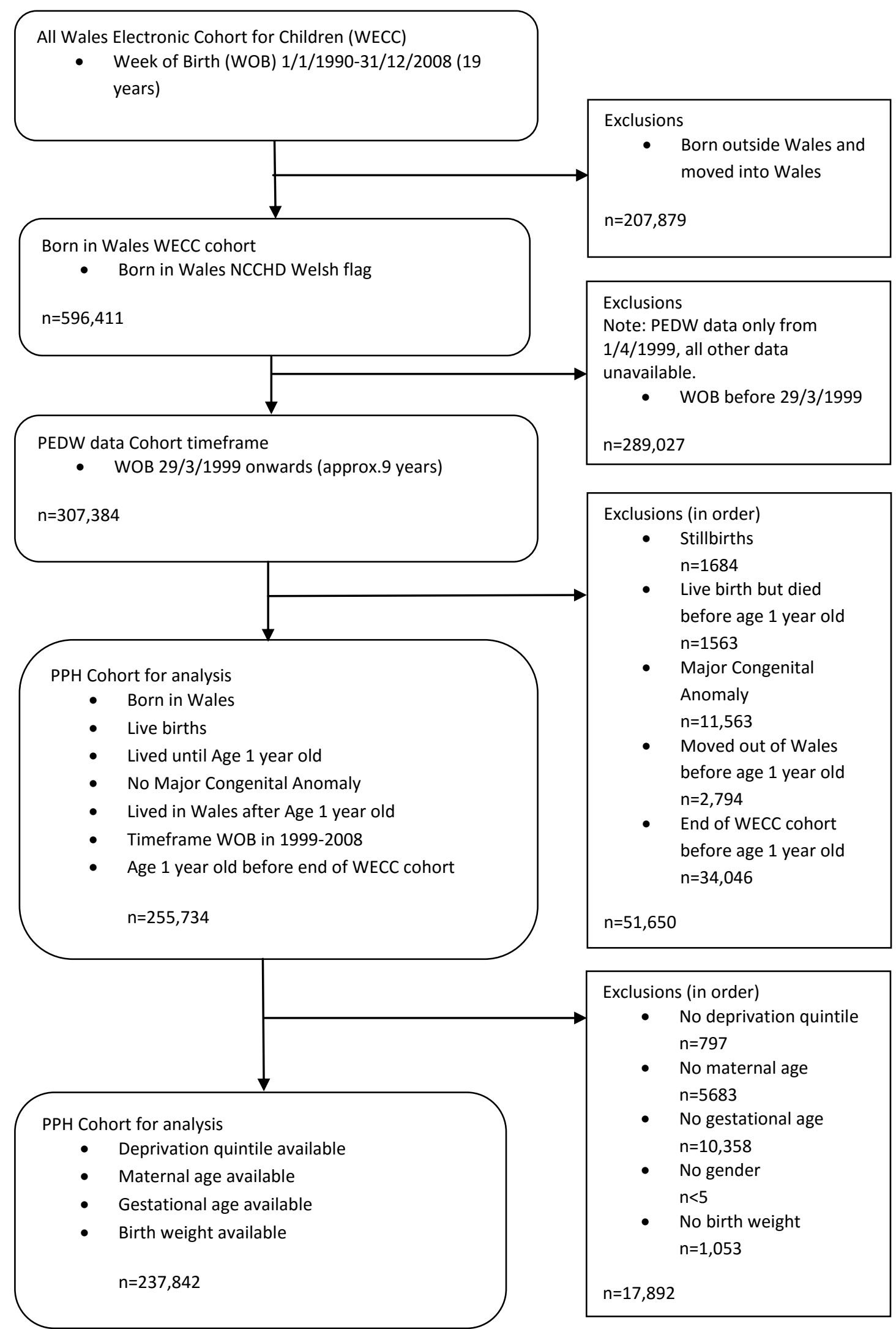


Table 1: ICD-10 codes for potentially preventable hospitalizations $(\mathrm{PPH})^{1420-22}$

\begin{tabular}{|c|c|c|}
\hline Category & ICD-10 code & $\begin{array}{c}\text { Additional } \\
\text { information }\end{array}$ \\
\hline \multicolumn{3}{|l|}{ Vaccine preventable } \\
\hline Influenza and pneumonia & $\begin{array}{l}\text { J10, J11, J13, J14, J15.3, } \\
\text { J15.4, J15.7, J15.9, J16.8, } \\
\text { J18.1, J18.8 }\end{array}$ & $\begin{array}{l}\text { In any diagnosis field; } \\
\text { exclude people under } 2 \\
\text { months; ICD-10-AM; } \\
\text { exclude cases with } \\
\text { secondary diagnosis of } \\
\text { D57 (sickle-cell } \\
\text { disorders) }\end{array}$ \\
\hline $\begin{array}{l}\text { Other vaccine preventable } \\
\text { conditions }\end{array}$ & $\begin{array}{l}\text { A35, A36, A37, A80, } \\
\text { B05, B06, B16.1, B16.9, } \\
\text { B18.0, B18.1, B26, } \\
\text { G00.0, M01.4 }\end{array}$ & In any diagnosis field \\
\hline Asthma & $\mathrm{J} 45, \mathrm{~J} 46$ & $\begin{array}{l}\text { Principal diagnosis } \\
\text { only }\end{array}$ \\
\hline $\begin{array}{l}\text { Dehydration and } \\
\text { gastroenteritis }\end{array}$ & $\begin{array}{l}\text { A09.9, E86, K52.2, } \\
\text { K52.8, K52.9 }\end{array}$ & $\begin{array}{l}\text { Principal diagnosis } \\
\text { only }\end{array}$ \\
\hline $\begin{array}{l}\text { Ear, nose and throat } \\
\text { infections }\end{array}$ & $\begin{array}{l}\text { H66, H67, J02, J03, J06, } \\
\text { J31.2 }\end{array}$ & $\begin{array}{l}\text { Principal diagnosis } \\
\text { only }\end{array}$ \\
\hline Dental conditions & $\begin{array}{l}\text { A69.0, K02, K03, K04, } \\
\text { K05, K06, K08, K09.8, } \\
\text { K09.9, K12, K13 }\end{array}$ & $\begin{array}{l}\text { Principal diagnosis } \\
\text { only }\end{array}$ \\
\hline $\begin{array}{l}\text { Appendicitis with } \\
\text { generalised peritonitis }\end{array}$ & $\mathrm{K} 35$ & In any diagnosis field \\
\hline Convulsions and epilepsy & G40, G41, O15, R56 & $\begin{array}{l}\text { Principal diagnosis } \\
\text { only }\end{array}$ \\
\hline \multicolumn{3}{|l|}{ Injuries and poisoning } \\
\hline $\begin{array}{l}\text { All injuries (Falls, fire/hot } \\
\text { object or substance; Motor } \\
\text { Vehicle Traffic Collision } \\
\text { (MVTC); MVTC- } \\
\text { pedestrian only; } \\
\text { poisoning) }\end{array}$ & V01-Y36 & In any diagnosis field \\
\hline
\end{tabular}


Table 2: Negative binomial model of the frequency of the frequency of moving home from Age 0 to $<1$ year an between the ages of 1 and 5 years $(n=237,842)$

\begin{tabular}{|c|c|c|c|c|c|c|c|}
\hline \multirow[t]{3}{*}{ Characteristics } & & & \multicolumn{5}{|c|}{ All emergency PPH Age 1 to less than 5} \\
\hline & & \multirow{2}{*}{$\begin{array}{c}\text { Total } \\
\mathrm{N}\end{array}$} & \multicolumn{2}{|c|}{$1+$ admission } & \multicolumn{3}{|c|}{$\begin{array}{l}\text { Negative Binomial } \\
\text { Regression } ¥ \\
\text { Univariate }\end{array}$} \\
\hline & & & $\mathrm{n}$ & $(\%)$ & IRR+ & $95^{\circ}$ & \\
\hline Frequency of moving home & 0 & 201114 & 26984 & (13.4) & 1.00 & & \\
\hline \multirow[t]{2}{*}{ Age $0-<1$ year } & 1 & 31735 & 4792 & (15.1) & 1.19 & 1.15 & 1.23 \\
\hline & $2+$ & 4993 & 800 & $(16.0)$ & 1.44 & 1.34 & 1.55 \\
\hline \multirow{2}{*}{ Gender } & Male & 121843 & 18298 & $(15.0)$ & 1.00 & & \\
\hline & Female & 115999 & 14278 & (12.3) & 0.79 & 0.78 & 0.81 \\
\hline \multirow[t]{2}{*}{ Parity } & 0 & 57849 & 7975 & $(13.8)$ & 1.00 & & \\
\hline & $1+$ & 179993 & 24601 & (13.7) & 1.00 & 0.97 & 1.02 \\
\hline \multirow[t]{6}{*}{ Maternal Age at birth } & $<20$ & 22874 & 4157 & (18.2) & 1.39 & 1.33 & 1.44 \\
\hline & $20-24$ & 52098 & 8204 & (15.7) & 1.22 & 1.18 & 1.26 \\
\hline & $25-29$ years old & 63877 & 8586 & (13.4) & 1.00 & & \\
\hline & $30-34$ & 62896 & 7535 & (12.0) & 0.87 & 0.84 & 0.90 \\
\hline & $35-39$ & 30328 & 3460 & (11.4) & 0.86 & 0.82 & 0.89 \\
\hline & $40+$ & 5769 & 634 & $(11.0)$ & 0.84 & 0.78 & 0.91 \\
\hline \multirow[t]{3}{*}{ Gestational Age at birth } & 24-32 weeks & 3070 & 639 & $(20.8)$ & 1.84 & 1.69 & 2.01 \\
\hline & $33-36$ & 12913 & 2039 & $(15.8)$ & 1.24 & 1.18 & 1.30 \\
\hline & $37-40+$ weeks & 221859 & 29898 & (13.5) & 1.00 & & \\
\hline \multirow[t]{3}{*}{ Maternal Cigarette smoking } & No & 68232 & 9140 & (13.4) & 1.00 & & \\
\hline & Yes & 21765 & 3666 & $(16.8)$ & 1.25 & 1.20 & 1.31 \\
\hline & no answer§ & 147845 & 19770 & (13.4) & 0.98 & 0.96 & 1.00 \\
\hline \multirow{3}{*}{$\begin{array}{l}\text { Breast feeding at birth / at 6-8 } \\
\text { weeks }\end{array}$} & No & 87312 & 13059 & $(15.0)$ & 1.00 & & \\
\hline & Yes & 111823 & 14135 & (12.6) & 0.84 & 0.82 & 0.86 \\
\hline & no answer§ & 38707 & 5382 & (13.9) & 0.83 & 0.80 & 0.85 \\
\hline
\end{tabular}




\begin{tabular}{|c|c|c|c|c|c|c|c|}
\hline \multirow{5}{*}{$\begin{array}{l}\text { Townsend Quintile of LSOA at } \\
\text { birth/first } 4 \text { months } \S \S\end{array}$} & 1 & 41060 & 4867 & (11.9) & 1.00 & & \\
\hline & 2 & 41544 & 5174 & (12.5) & 1.05 & 1.00 & 1.09 \\
\hline & 3 & 45718 & 6270 & (13.7) & 1.19 & 1.15 & 1.24 \\
\hline & 4 & 49142 & 7026 & (14.3) & 1.26 & 1.21 & 1.31 \\
\hline & 5 & 60378 & 9239 & (15.3) & 1.35 & 1.30 & 1.40 \\
\hline \multirow{2}{*}{$\begin{array}{l}\text { Multiple births } \\
\text { eg: twins }\end{array}$} & No & 231699 & 31776 & (13.7) & 1.00 & & \\
\hline & Yes & 6143 & 800 & (13.0) & 0.98 & 0.91 & 1.05 \\
\hline \multirow[t]{2}{*}{ Congenital anomaly } & None & 232454 & 31648 & (13.6) & 1.00 & & \\
\hline & Minor & 5388 & 928 & $(17.2)$ & 1.35 & 1.26 & 1.45 \\
\hline \multirow{2}{*}{ Small for gestational age $<10 \%$} & No & 214812 & 29155 & (13.6) & 1.00 & & \\
\hline & Yes & 23030 & 3421 & $(14.9)$ & 1.11 & 1.06 & 1.15 \\
\hline \multirow[t]{2}{*}{ Caesarean section } & No & 183231 & 24767 & $\begin{array}{l}(13.5) \\
\end{array}$ & 1.00 & & \\
\hline & Yes & 54611 & 7809 & (14.3) & 1.09 & 1.06 & 1.12 \\
\hline
\end{tabular}

*All Avoidable Admissions statistically significant $\mathrm{p} \leq 0.05$ in chi square or univariate analysis.

$¥$ Negative binomial model used with person years to account for differential loss to follow-up of the outcome $\mathrm{m}$ (post 31/8/2008), house move out of Wales and death.

$+\mathrm{IRR}=$ Person-years Incidence Rate Ratio.

$\sim$ One no answer case excluded; § Included as high levels of missing data.

\# Adjusted for all variables in the table; $\partial$ Breastfeeding and maternal cigarette smoking imputed.

$\S \S$ The first quintile denoted the least deprived group through to the fifth denoting the most deprived. 
Table 3. Negative binomial model of the frequency of moving home from age 0 to $<1$ year and all emergency PPH between the ages of 1 and 5 years $(n=237,842)$

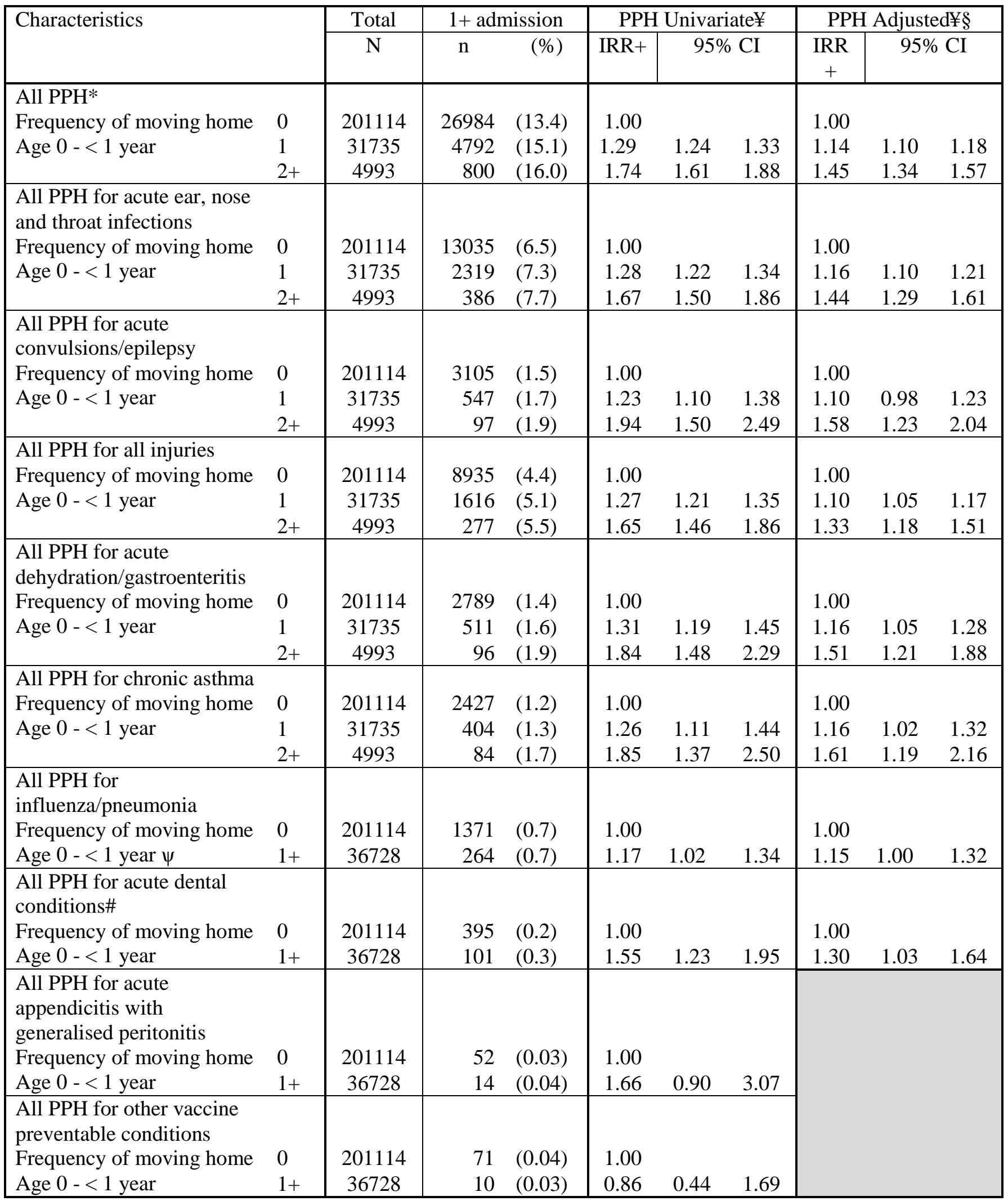


2 *All Avoidable Admissions significant $\mathrm{p} \leq 0.05$ in chi square or univariate analysis.

3 ¥Negative binomial model used with person years to account for differential loss to follow-up of

4 the outcome measure from end of cohort (post 31/8/2008), a house move after age 1 year or

5 death.

$6+\mathrm{IRR}=$ Person-years Incidence Rate Ratio; $\mathrm{PPH}=$ Potentially preventable hospitalizations.

7 §Adjusted for all variables in the main model, but without imputation due to small counts

8 \#Dental model adjusted only for parity, maternal age, townsend quintiles at birth/4 months and

9 cigarette smoking due to small numbers of PPH for acute dental conditions.

$10 \psi$ Adjusted IRR for PPH for influenza/pneumonia 1+ house move in first year of life has

$11 \mathrm{p}=0.055$.

12 
Table 4. Potentially preventable emergency hospitalization incidence rates by year of follow-up and house move $(n=237,842)$

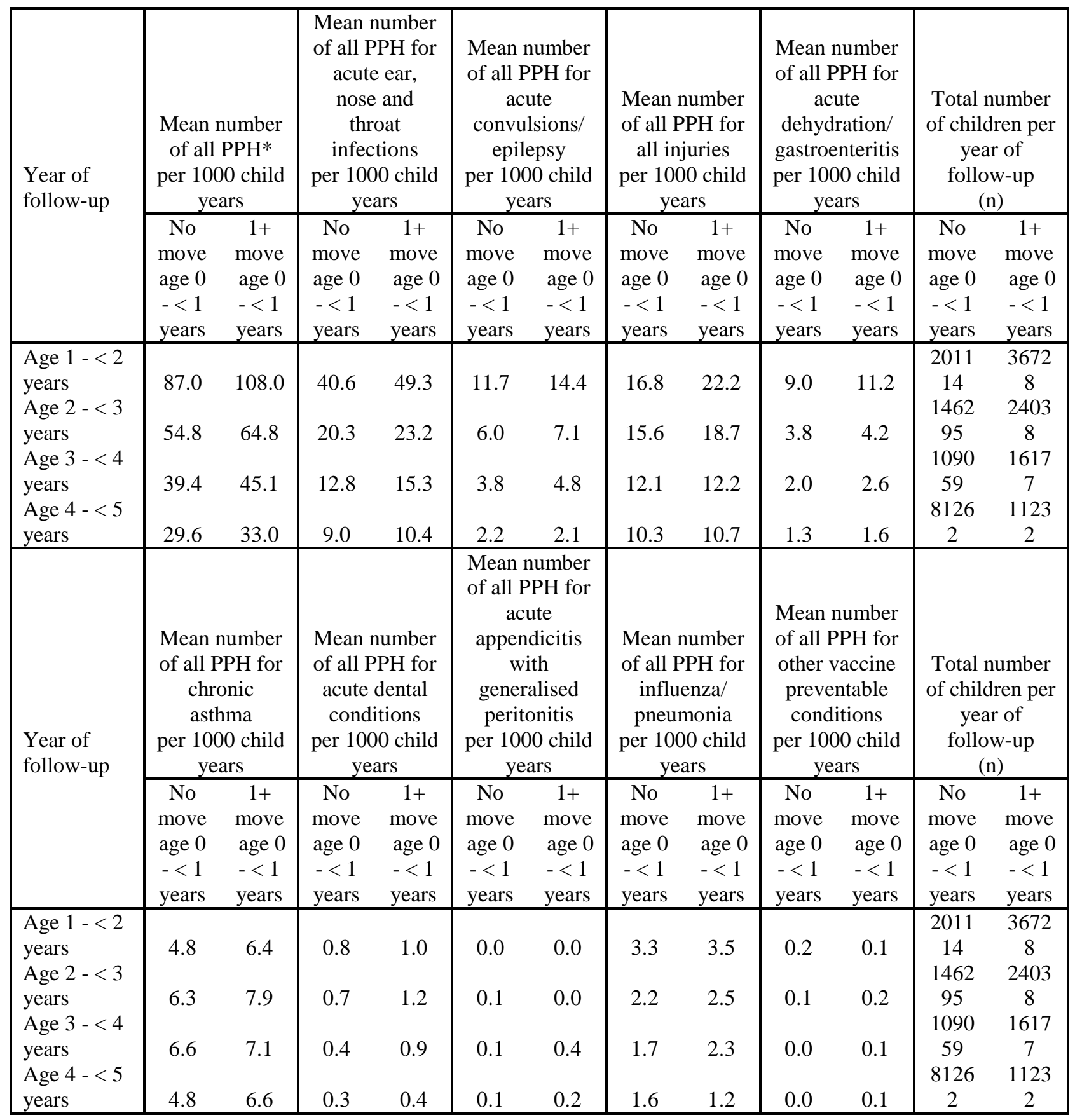

*All Avoidable Admissions statistically significant $\mathrm{p} \leq 0.05$ in chi square or univariate analysis. 